\title{
A Novel HPLC Method for the Concurrent Analysis and Quantitation of Seven Water-Soluble Vitamins in Biological Fluids (Plasma and Urine): A Validation Study and Application
}

\author{
Margherita Grotzkyj Giorgi, ${ }^{1}$ Kevin Howland, ${ }^{2}$ Colin Martin, ${ }^{3}$ and Adrian B. Bonner ${ }^{1}$ \\ ${ }^{1}$ Centre for Health Services Studies, University of Kent, Canterbury, Kent CT2 7NF, UK \\ ${ }^{2}$ Department of Biosciences, University of Kent, Canterbury, Kent CT2 7PD, UK \\ ${ }^{3}$ School of Health, Nursing and Midwifery, University of the West of Scotland, Ayr Campus, Ayr KA8 0SX, Scotland, UK
}

Correspondence should be addressed to Margherita Grotzkyj Giorgi, mg209@kent.ac.uk

Received 10 October 2011; Accepted 30 November 2011

Academic Editors: D. Agbaba and M. Mahmoud

Copyright (C) 2012 Margherita Grotzkyj Giorgi et al. This is an open access article distributed under the Creative Commons Attribution License, which permits unrestricted use, distribution, and reproduction in any medium, provided the original work is properly cited.

\begin{abstract}
An HPLC method was developed and validated for the concurrent detection and quantitation of seven water-soluble vitamins $\left(\mathrm{C}, \mathrm{B}_{1}, \mathrm{~B}_{2}, \mathrm{~B}_{5}, \mathrm{~B}_{6}, \mathrm{~B}_{9}, \mathrm{~B}_{12}\right)$ in biological matrices (plasma and urine). Separation was achieved at $30^{\circ} \mathrm{C}$ on a reversed-phase $\mathrm{C} 18$ A column using combined isocratic and linear gradient elution with a mobile phase consisting of $0.01 \%$ TFA aqueous and $100 \%$ methanol. Total run time was 35 minutes. Detection was performed with diode array set at $280 \mathrm{~nm}$. Each vitamin was quantitatively determined at its maximum wavelength. Spectral comparison was used for peak identification in real samples (24 plasma and urine samples from abstinent alcohol-dependent males). Interday and intraday precision were $<4 \%$ and $<7 \%$, respectively, for all vitamins. Recovery percentages ranged from $93 \%$ to $100 \%$.
\end{abstract}

\section{Introduction}

Water-soluble vitamins include $B$ group vitamins $\left(B_{1}, B_{2}\right.$, $\mathrm{B}_{3}, \mathrm{~B}_{5}, \mathrm{~B}_{6}, \mathrm{~B}_{9}, \mathrm{~B}_{12}$ ) and ascorbic acid (vitamin C). Vitamins are micronutrients that are essential to life, and many of them play an important role in regulation of brain functioning (e.g., vitamin $B_{1}$ deficiency causes biochemical brain lesions that causes Wernicke's encephalopathy, an acute neuropsychiatric condition often observed in chronic alcohol abusers [3]).

The reference methods for vitamins analysis in biological fluids are often based on time-consuming microbiological assays that may lack specificity [4]. In addition, vitamin extraction involves pretreatment through complex chemical reactions followed by individual methods for the determination of each vitamin. During the last decades, there has been an increasing interest for the simultaneous determination of vitamins. Thus, various analytical methods have been developed over recent years [5-9]. A number of recent studies have focused on validation of analytical methodologies for multivitamins analysis but the vast majority of them applied their methods to analysis of food matrices, drinks, polyvitaminated premixes, and vitamins supplements $[10,11]$. On the other hand, only a relatively small number of experimental studies focused on validation of analytical methodologies for multivitamins analysis in biological samples (blood and urine) and with limited results in terms of lengthy sample preparation steps and method's robustness and reproducibility [8]. Because of this lack of a robust and validated analytical test for multivitamin analysis in biological samples in routine clinical assessment and in those investigations where a timely and robust analytical method is needed, the aim of this study was to develop and validate a novel HPLC methodology for rapid detection and quantitation of seven water-soluble vitamins $\left(B_{1}, B_{2}\right.$, $\mathrm{B}_{5}, \mathrm{~B}_{6}, \mathrm{~B}_{9}, \mathrm{~B}_{12}, \mathrm{C}$ ) in biological fluids (plasma and urine). The validated method was then applied to quantify watersoluble vitamins in plasma and urine samples obtained from 24 abstinent alcohol-dependent males. 


\section{Materials and Methods}

2.1. Standards and Reagents. Water-soluble vitamins employed in this study $\left(B_{1}, B_{2}, B_{3}, B_{5}, B_{6}\right.$ as pyridoxal phosphate [5'-PLP], $\mathrm{B}_{9}, \mathrm{~B}_{12}$ and $\mathrm{C}$ ) and the internal standard (theobromine) were purchased from Sigma-Aldrich, Gillingham, UK, and were of the highest grade of purity available (>95\%). Methanol, ethanol (HPLC grade), and nhexane were obtained from Fisher Scientific, Loughborough, UK. Trifluoroacetic acid (TFA) of protein chemistry grade (>99.5\%) was purchased from Thermo Scientific, Fisher Scientific, Loughborough, UK. Ultra pure HPLC grade water (Maxima water purification system, USF Elga, High Wycombe, UK) was used throughout the entire protocol.

2.2. Chromatographic Conditions. An Agilent 1100 chromatographic system (Agilent Ltd., South Queensferry, UK) was used for the analysis and quantitation of vitamins in biological samples. The ChemStation software controlled the whole chromatographic system.

Vitamins were separated on a reversed-phase chromatographic column MetaChem Polaris C18-A ( $5 \mu \mathrm{m}, 250 \mathrm{~mm} \times$ $2.1 \mathrm{~mm}$ i.d., Varian medical system Ltd, Crawley, UK) fitted with a precolumn (MetaGuard column, C18-A, Varian medical system Ltd, Crawley, UK) using combined isocratic and linear gradient elution with a mobile phase consisting of $0.01 \%$ TFA aqueous ( $\mathrm{pH} 2.9$, solvent $\mathrm{A}$ ) and 100\% methanol (solvent B). Linear gradient profile (A:B) started at 95:5 and it was kept constant for the first 4 minutes, then linearly decreased up to 2:98 during the next 6 minutes, then it was kept constant in the next 20 minutes and finally linearly increased up to $95: 5$ in the last 5 minutes of separation. Total run time was 35 minutes. This gradient was utilised for temperature studies; subsequently, the timing of gradient was modified to suit reduced analysis time. The flow rate was adjusted to $0.2 \mathrm{~mL} / \mathrm{min}$. Injection volume was $3 \mu \mathrm{L}$. Column temperature was kept constant at $30^{\circ} \mathrm{C}$. Detection was performed with a photodiode array detector monitoring the eluent at $280 \mathrm{~nm}$; however, quantitation was performed at maximum wavelength for each vitamin as follows: $230 \mathrm{~nm}$ for ascorbic acid, $270 \mathrm{~nm}$ for thiamine, $265 \mathrm{~nm}$ for riboflavin, $256 \mathrm{~nm}$ for nicotinamide, $266 \mathrm{~nm}$ for pantothenic acid, $257 \mathrm{~nm}$ for pyridoxine, $280 \mathrm{~nm}$ for folic acid, and $230 \mathrm{~nm}$ for cyanocobalamin. Identification of resolved peaks in real samples was executed by comparing their spectra with those derived from aqueous standard solutions.

2.3. Standards Preparation. The aqueous stock solutions of water-soluble vitamins $\left(\mathrm{B}_{1}, \mathrm{~B}_{3}, \mathrm{~B}_{5}, \mathrm{~B}_{6}\right.$ as pyridoxal phosphate [5'-PLP], B $\left., B_{12}, C\right)$ were prepared weekly by weighting $10 \mathrm{mg}$ of each vitamin in a volumetric cylinder in $100 \mathrm{~mL}$ of ultrapure water (Maxima water, USF Elga, High Wycombe, UK) containing $0.01 \%$ of trifluoroacetic acid (TFA). Vitamin $\mathrm{B}_{2}$ was prepared by weighting $5 \mathrm{mg}$ and subsequently added to the multivitamin solution (final concentration of riboflavin was $\left.50 \mathrm{ng} \mu \mathrm{L}^{-1}\right)$. After brief agitation, solution was transferred by pouring into an amber-glass bottle for storage at $+4^{\circ} \mathrm{C}$. The final concentration of each vitamin was
$100 \mathrm{ng} \mu \mathrm{L}^{-1}$ (except vitamin $\mathrm{B}_{2}$ which was $50 \mathrm{ng} \mu \mathrm{L}^{-1}$ ). Vitamin $\mathrm{B}_{9}$ solution was prepared by weighting $5 \mathrm{mg}$ of powdered Vitamin $\mathrm{B}_{9}$ in a volumetric cylinder and dissolved in $100 \mathrm{~mL}$ of $1 \mathrm{M} \mathrm{NaHCO}_{3}$. All solutions were stored in a refrigerator in amber-glass bottles to protect vitamins from light-induced oxidation. Working standard solutions were prepared fresh daily from stock solutions. Final concentration of watersoluble vitamins standards ranged from 0.25 to $25 \mathrm{ng} \mu \mathrm{L}^{-1}$ ( six concentration levels). Theobromine (internal standard) was used at a concentration of $2 \mathrm{ng} \mu \mathrm{L}^{-1}$.

2.4. Sample Preparation. Experiments were carried out to identify a sample preparation procedure that would allow simultaneous detection of seven water-soluble vitamins in biological samples. Aliquots of one spiked plasma sample (final concentration of each water-soluble vitamins: $20 \mathrm{ng} \mu \mathrm{L}^{-1}$ ) were concomitantly processed following one of these three procedures: deproteinisation with $400 \mu \mathrm{L}$ pure acetonitrile followed by solid phase extraction. The solid phase extraction method was obtained from [8]. The second methodology involved liquid-liquid extraction method $[600 \mu \mathrm{L} n$-hexane $+150 \mu \mathrm{L}$ ethanol : methanol, $95: 5$, $\mathrm{v} / \mathrm{v}$ ] with no solid phase extraction. The third methodology involved deproteinisation with $600 \mu \mathrm{L}$ ethanol:methanol, $95: 5, \mathrm{v} / \mathrm{v}$ followed by solid phase extraction procedure as per [8]. Experiments were run in triplicate.

The first methodology was performed following the procedure reported in [8] with the minor modification of using $400 \mu \mathrm{L}$ of pure acetonitrile in a $1: 1$ ratio $(\mathrm{v} / \mathrm{v})$ to fresh or freshly thawed plasma previously spiked with internal standard (theobromine, $2 \mathrm{ng} \mu \mathrm{L}^{-1}$ ).

The second methodology was carried out by transferring to a glass analysis tube $400 \mu \mathrm{L}$ of fresh or freshly thawed plasma containing IS. Six hundred microliters of pure $n$-hexane were added and tubes were briefly vortex mixed. The addition of hexane was used to extract lipidsoluble matrix components that may interfere with vitamins analysis. Tubes were then centrifuged at 4,000 rpm for 5 minutes at $4^{\circ} \mathrm{C}$. After centrifugation was complete, $150 \mu \mathrm{L}$ of ethanol:methanol $(95: 5, \mathrm{v} / \mathrm{v})$ was added to the tubes and centrifuged at $23,000 \mathrm{rpm}$ for 15 minutes at $4^{\circ} \mathrm{C}$. The upper layer (organic phase) was discarded. The lower layer (aqueous phase) was collected and placed in a new, capped microcentrifuge tube. Tubes were placed in a SpeedVac instrument (Thermo Scientific, Fisher Scientific, Loughborough, UK) to dry. When the supernatant from the aqueous phase was completely dried, samples were resuspended in two HPLC vials containing $0.01 \%$ TFA in water. No solid phase extraction procedure was carried out prior to HPLC injection.

The third methodology was carried out by adding $600 \mu \mathrm{L}$ of ethanol:methanol $(95: 5, \mathrm{v} / \mathrm{v})$ to $400 \mu \mathrm{L}$ of fresh or freshly thawed plasma. Samples were vortex-mixed briefly (30 seconds) and samples were centrifuged at 15,000 rpm for 15 minutes at $4^{\circ} \mathrm{C}$. Supernatant was carefully collected and placed in a new capped microcentrifuge tube and placed in a SpeedVac instrument. When dry, samples were resuspended in water: methanol $(50: 50, \mathrm{v} / \mathrm{v})$ before application to solid 
TABLE 1: Column temperatures study. Experimental results (peak area mean \pm RSD) obtained from six separate runs of a standard sample (aqueous mixture of 8 water-soluble vitamins) at 4 different column temperatures. The last row of the table reports run time in minutes. HPLC conditions used were those reported in the main text.

\begin{tabular}{lcccc}
\hline Vitamin & $\begin{array}{c}\text { Peak area [mAU] } \pm \text { R.S.D. } \\
\text { measured at } 280 \mathrm{~nm} \text { at } \\
\text { column temperature of } 20^{\circ} \mathrm{C}\end{array}$ & $\begin{array}{c}\text { Peak area [mAU] } \pm \text { R.S.D. } \\
\text { measured at } 280 \mathrm{~nm} \text { at } \\
\text { column temperature of } 25^{\circ} \mathrm{C}\end{array}$ & $\begin{array}{c}\text { Peak area [mAU] } \pm \text { R.S.D. } \\
\text { measured at 280 nm at } \\
\text { column temperature of } 30^{\circ} \mathrm{C}\end{array}$ & $\begin{array}{c}\text { Peak area [mAU] } \pm \text { R.S.D. } \\
\text { measured at } 280 \mathrm{~nm} \text { at } \\
\text { column temperature of } 40^{\circ} \mathrm{C}\end{array}$ \\
\hline $\mathrm{C}$ & $367.09 \pm 0.03$ & $333.94 \pm 0.01$ & $364.98 \pm 0.04$ & $143.68 \pm 0.02$ \\
$\mathrm{~B}_{1}$ & $168.78 \pm 0.01$ & $247.25 \pm 0.03$ & $169.66 \pm 0.05$ & $50.68 \pm 0.06$ \\
$\mathrm{~B}_{2}$ & $2065.76 \pm 0.07$ & $1681.83 \pm 0.05$ & $2138.75 \pm 0.02$ & $375.47 \pm 0.03$ \\
$\mathrm{~B}_{3}$ & $88.15 \pm 0.03$ & $89.61 \pm 0.05$ & $92.60 \pm 0.02$ & $44.51 \pm 0.08$ \\
$\mathrm{~B}_{5}$ & $51.05 \pm 0.03$ & $50.73 \pm 0.08$ & $60.13 \pm 0.03$ & $22.19 \pm 0.09$ \\
$\mathrm{~B}_{6}$ & $889.06 \pm 0.02$ & $924.11 \pm 0.06$ & $878.72 \pm 0.08$ & $191.70 \pm 0.07$ \\
$\mathrm{~B}_{9}$ & $181.25 \pm 0.06$ & $156.71 \pm 0.05$ & $205.21 \pm 0.02$ & $73.20 \pm 0.03$ \\
$\mathrm{~B}_{12}$ & $310.10 \pm 0.02$ & $532.52 \pm 0.03$ & $738.66 \pm 0.05$ & $574.27 \pm 0.07$ \\
\hline Total analysis & $25 \mathrm{~min}$ & $25 \mathrm{~min}$ & $35 \mathrm{~min}$ & $45 \mathrm{~min}$ \\
time [mins] & & &
\end{tabular}

TABLE 2: System suitability test results for the optimised HPLC method for determination of water-soluble vitamins in biological matrices (column temperature $=30^{\circ} \mathrm{C}$; flow rate $=0.2 \mathrm{~mL} \mathrm{~min}^{-1}$ ). Mean peak areas of 5 injections of aqueous standard solution containing $20 \mathrm{ng} \mathrm{mL}^{-1}$ of each water-soluble vitamin.

\begin{tabular}{|c|c|c|c|c|c|c|c|}
\hline Vitamin & $\begin{array}{l}\text { Retention time } \\
(\min )^{\mathrm{a}}(\% \mathrm{CV})^{\mathrm{b}}\end{array}$ & $\begin{array}{c}\text { Capacity factor } \\
\left(\mathrm{K}^{\prime}\right)\end{array}$ & Selectivity $(\alpha)$ & Resolution $\left(R_{s}\right)$ & Tailing factor & plate count & $\begin{array}{c}\text { Mean peak areas } \\
(\mathrm{mAU})^{\mathrm{c}} \\
(\% \mathrm{CV})^{\mathrm{b}}\end{array}$ \\
\hline $\mathrm{C}$ & $3.5(0.9)$ & 1.72 & 1.20 & 2.88 & 0.79 & 3111 & $365(0.01)$ \\
\hline $\mathrm{B}_{1}$ & $4.3(0.7)$ & 2.21 & 1.15 & 2.65 & 0.77 & 4943 & $170(0.03)$ \\
\hline $\mathrm{B}_{3}$ & $5.3(1.1)$ & 2.79 & 1.17 & 3.13 & 0.80 & 6056 & $93(0.02)$ \\
\hline $\mathrm{B}_{6}(\mathrm{PLP})$ & $6.1(0.99)$ & 3.86 & 1.83 & 1.89 & 0.56 & 4255 & $879(0.001)$ \\
\hline $\mathrm{B}_{5}$ & $6.8(0.29)$ & 3.36 & 1.15 & 2.54 & 0.85 & 7050 & $60(0.05)$ \\
\hline $\mathrm{B}_{9}$ & $13(0.07)$ & 8.29 & 1.03 & 1.60 & 0.46 & 6735 & $205(0.01)$ \\
\hline $\mathrm{B}_{12}$ & $13.4(0.6)$ & 8.57 & 1.03 & 1.27 & 0.42 & 2329 & $740(0.007)$ \\
\hline $\mathrm{B}_{2}$ & $13.8(0.2)$ & 8.86 & 1.07 & 1.30 & 0.46 & 1096 & $2140(0.001)$ \\
\hline
\end{tabular}

${ }^{\mathrm{a}}$ The retention time of unretained peak is $1.4 \mathrm{~min}$.

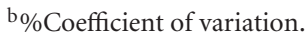

${ }^{\mathrm{c}}$ milli Arbitrary Unit.

phase cartridge. Solid phase extraction was carried out following the procedure reported in [8].

The same procedures were also used for urine samples with no modification.

2.5. Solid-Phase Extraction Procedure. Solid-phase extraction (SPE) procedure was carried out following the protocol described by Chatzimichalakis and colleagues [8] with no modifications.

\subsection{Method Development}

2.6.1. Temperature Studies. Temperature studies were carried out to evaluate the run temperature that provides the best peak resolution in least time. Five HPLC injections were performed from one standard solution of water-and lipidsoluble vitamins and internal standard and the experiment was run in triplicate for each selected temperature $(20,25$, 30 , and $40^{\circ} \mathrm{C}$ ).
2.6.2. System Suitability. The system suitability was evaluated by five replicate analyses of a standard aqueous mixture of water-soluble vitamins ( $20 \mathrm{ng} \mu \mathrm{L}^{-1}$ each vitamin). The acceptance limit was $\pm 5 \%$ for the percent coefficient of variation $(\% \mathrm{CV})$ of the peak area and the retention time of water-soluble vitamins.

2.6.3. Linearity (Calibration Curve). Three calibration curves were constructed on three consecutive days. Linearity was tested by running six standard mixtures of water-soluble vitamins, at final on-column concentrations of $0.5,1,2,5$, 10,15 , and $20 \mathrm{ng} \mu \mathrm{L}^{-1}$. The internal standard, theobromine, was kept at a constant concentration of $2 \mathrm{ng} \mu \mathrm{L}^{-1}$.

2.6.4. Accuracy. Accuracy, defined as the nearness of the true value and found value, was evaluated as \%bias for watersoluble vitamins according to the following equation:

$$
\text { \%accuracy }=\frac{\text { observed concentration }}{\text { nominal concentration }} \times 100 \text {. }
$$


2.6.5. Specificity. The specificity of an analytical method may be defined as the ability to detect the analyte peak in the presence of all the matrix components. In this case, a standard aqueous solution of water-soluble vitamins and the internal standard at known concentration $\left(20 \mathrm{ng} \mu \mathrm{L}^{-1}\right.$ and $2 \mathrm{ng} \mu \mathrm{L}^{-1}$, resp.) were spiked in a matrix of simulated plasma (composition obtained from [12]). Simulated plasma samples were processed as real plasma samples.

2.6.6. Precision. Precision of the assay was determined by repeatability and intermediate precision for 3 consecutive days. Four different concentrations of water-soluble vitamins $\left(2,5,10\right.$, and $\left.15 n g \mu \mathrm{L}^{-1}\right)$ were analysed in five independent series during the same day (intraday precision) and over 3 consecutive days (intermediate precision). Every sample was injected three times.

2.6.7. Limits of Detection and Quantitation (Sensitivity). Limit of detection (LOD) and limit of quantitation (LOQ) were estimated from the signal-to-noise ratio. LOD is defined as the lowest concentration resulting in a peak area of three times the baseline noise. LOQ is defined as the lowest concentration that provides a signal-to-noise ratio higher than 10 , with precision (\%CV) and accuracy (\%bias) within their acceptable range $(10 \%)$.

2.6.8. Stability. The stability of the water-soluble vitamins solution was determined by analyzing standard aqueous solutions and spiked, simulated plasma samples after a shortterm storage at controlled room temperature $\left(20-25^{\circ} \mathrm{C}\right)$ and at $+4^{\circ} \mathrm{C}$ for 12 and $24 \mathrm{~h}$. The long-term stability was determined by analysing samples stored at $+4^{\circ} \mathrm{C}$ for 30 days. The autosampler stability was determined by analysing the samples after $24 \mathrm{~h}$ of storage in the autosampler (set at $+4^{\circ} \mathrm{C}$ $\left.\pm 2^{\circ} \mathrm{C}\right)$.

2.6.9. Recovery Studies. The percentage recovery rate (\% recovery) was calculated using the experimental response values and values provided by the calibration curves for the same quantity of analyte. Student's $t$-test was performed to assess whether the recovery rate was significantly different from $100 \%$ at $P<0.05$.

2.7. Statistical Analysis. Data collected in this study were analysed using SPSS version 17 statistical package by oneway analysis of variance (ANOVA) and by independentsamples Student's $t$-test. Univariate linear regression analysis using least square method was applied to test the model. Correlation coefficient was calculated and the results of the statistical analysis were considered significant if their corresponding $P$ values were less than 0.05 .

\section{Results}

3.1. Temperature Study. A temperature study was conducted by analysing a standard mixture of water-soluble vitamins, at known concentration, using 4 column temperatures. Experiments were run in triplicate. Results are reported
TABLE 3: Method optimisation results. Results from the sample preparation method optimisation for vitamins spiked in artificial plasma samples processed using each of the three methods mentioned above. Results are reported as mean of peak area \pm RSD $(n=3)$. Numbers in parenthesis indicate wavelength used for quantitation.

\begin{tabular}{|c|c|c|}
\hline Vitamins (nm) & $\begin{array}{l}\text { Peak area } \\
{[\mathrm{mAU}]}\end{array}$ & $\begin{array}{c}\% \\
\text { RSD }\end{array}$ \\
\hline \multicolumn{3}{|c|}{$\begin{array}{l}200 \mu \mathrm{L} \text { pure acetonitrile }+ \text { solid phase } \\
\text { extraction }\end{array}$} \\
\hline C (230) & 150.92 & 2.6 \\
\hline $\mathrm{B}_{1}(270)$ & 62.60 & 1.7 \\
\hline $\mathrm{B}_{2}(265)$ & 366.16 & 10.3 \\
\hline $\mathrm{B}_{5}(266)$ & 27.14 & 0.4 \\
\hline $\mathrm{B}_{6}(257)$ & 110.28 & 2.4 \\
\hline $\mathrm{B}_{9}(280)$ & 69.13 & 2.0 \\
\hline $\mathrm{B}_{12}(230)$ & 179.13 & 5.2 \\
\hline \multicolumn{3}{|c|}{ L/L extraction_aqueous phase } \\
\hline $\mathrm{C}(230)$ & 197.91 & 4.7 \\
\hline $\mathrm{B}_{1}(270)$ & 64.10 & 2.9 \\
\hline $\mathrm{B}_{2}(265)$ & 216.31 & 6.0 \\
\hline $\mathrm{B}_{5}(266)$ & 14.83 & 0.2 \\
\hline $\mathrm{B}_{6}(257)$ & 145.07 & 9.4 \\
\hline $\mathrm{B}_{9}(280)$ & 112.93 & 0.9 \\
\hline $\mathrm{B}_{12}(230)$ & 132.36 & 2.6 \\
\hline \multicolumn{3}{|c|}{$\begin{array}{l}600 \mu \mathrm{L} \text { ethanol: methanol }(95: 5)+\text { solid-phase } \\
\text { extraction }\end{array}$} \\
\hline $\mathrm{C}(230)$ & 169.14 & 2.8 \\
\hline $\mathrm{B}_{1}(270)$ & 87.75 & 2.3 \\
\hline $\mathrm{B}_{2}(265)$ & 302.29 & 1.9 \\
\hline $\mathrm{B}_{5}(266)$ & 45.52 & 0.7 \\
\hline $\mathrm{B}_{6}(257)$ & 60.97 & 1.0 \\
\hline $\mathrm{B}_{9}(280)$ & 285.33 & 5.4 \\
\hline $\mathrm{B}_{12}(230)$ & 111.74 & 1.0 \\
\hline
\end{tabular}

in Table 1. Column temperature of $30^{\circ} \mathrm{C}$ was selected as an acceptable compromise between rapid separation (35 minutes) and analytes degradation measured as decreased detector response.

3.2. System Suitability. Results from system suitability studies are reported in Table 2.

3.3. Plasma Sample Extraction Method Development. A series of experiments were carried out to identify a sample preparation procedure that would allow simultaneous detection of eight water-soluble vitamins in plasma. Aliquots of one plasma sample spiked with water-soluble vitamins, $20 \mathrm{ng} \mu \mathrm{L}^{-1}$ each vitamin, were concomitantly processed following one of the three procedures detailed in Section 2. Experiments were run in triplicate. Results are reported in Table 3.

Results indicate that there was no statistically significant difference between the three sample preparation methods (Student's $t$-tests not significant, $P>0.05$ ), except for 


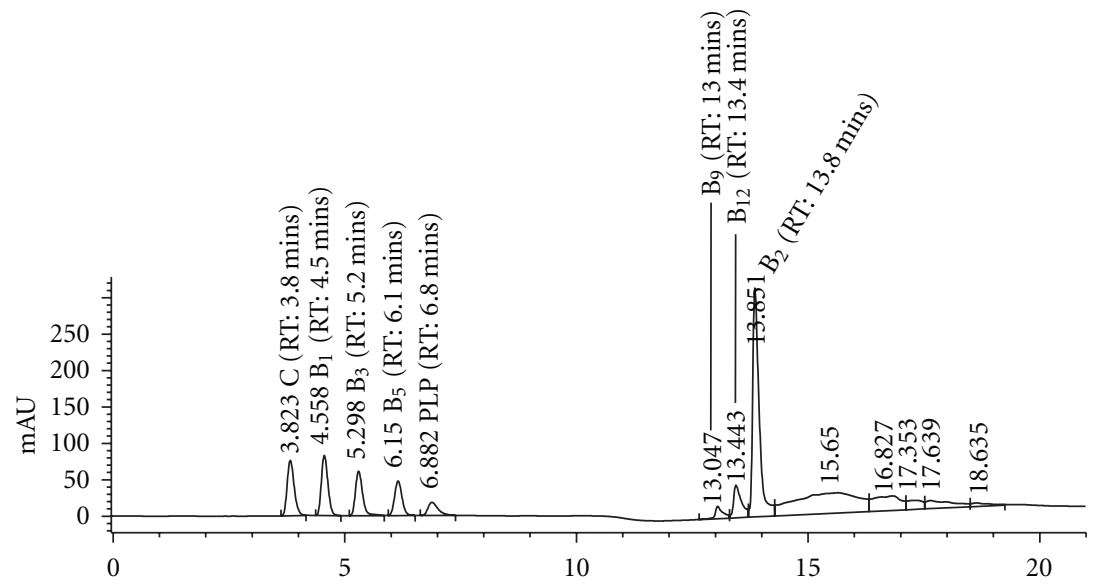

(a)
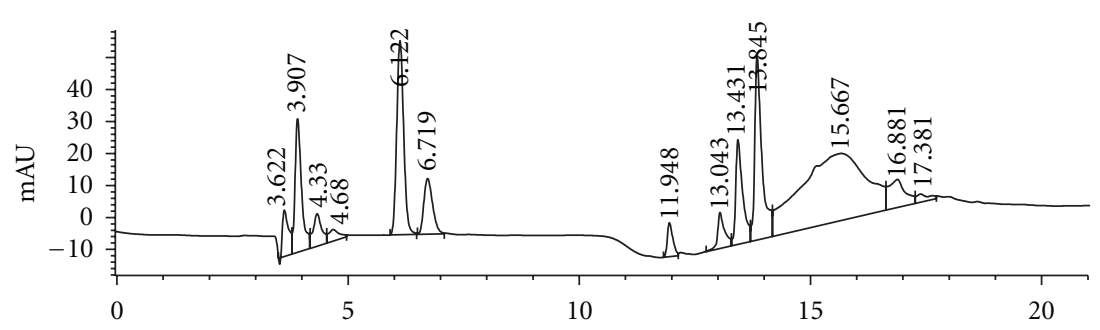

(b)

FIGURE 1: Vitamins mix (standards prepared in water, $20 \mathrm{ng} / \mu \mathrm{L}$ ) analysed under standardised conditions reported in the main text. (a) Real plasma sample obtained from one study participant analysed under standardised conditions reported in the main text. (b) Real plasma sample was spiked with the IS (RT: 11.948).

5 '-PLP when extracted with the second method (liquidliquid extraction) when compared with the third method (600 $\mu \mathrm{L}$ ethanol:methanol, 95:5, v/v, followed by solid phase extraction): the difference between peak areas was statistically significant beyond 5\% (Student's $t$-test, $P<$ 0.05 ; exact $P=0.017$ ). Specifically, $5^{\prime}$-PLP extraction was better with the second method in comparison to the third one (peak areas: $145.0723 \mathrm{mAU}$ and $60.97128 \mathrm{mAU}$, resp.). Unfortunately, when spiked in plasma sample, vitamin $B_{3}$ (nicotinamide) was not detectable by our method.

\section{Method Validation}

4.1. Specificity, Linearity, and Precision Studies. Representative chromatograms of standard solution and a real plasma sample are depicted in, respectively, Figures 1(a) and 1(b). Water-soluble vitamins elute in a specific order and in groups depending upon their chemical properties and interaction with the analytical column. As expected, polar vitamins (ascorbic acid, thiamin, nicotinamide and PLP) elute first, followed by pantothenic acid and finally by lowpolar vitamins (folic acid, cyanocobalamin and riboflavin). Retention times were as following: $3.5 \pm 0.03$ mins [C], $4.3 \pm$ 0.03 mins $\left[B_{1}\right], 5.3 \pm 0.06$ mins $\left[B_{3}\right], 6.1 \pm 0.06$ mins $\left[5^{\prime}-\right.$ PLP], $6.8 \pm 0.02$ mins [ $\mathrm{B}_{5}$ ], $12 \pm 0.02$ mins [theobromine, IS], $13 \pm 0.01$ mins $\left[\mathrm{B}_{9}\right], 13.4 \pm 0.08$ mins $\left[\mathrm{B}_{12}\right]$, and $13.8 \pm$ 0.03 mins $\left[B_{2}\right]$. As reported in Figure 1, peaks are well resolved and symmetric. Peak identification and purity were investigated by comparing UV spectra of each individual vitamin when analysed in mixtures and by running standard samples containing only one vitamin. When comparing standard chromatogram with chromatograms obtained from spiked artificial plasma, no major interference was noted from endogenous substances naturally present in human plasma. Two unidentified peaks were noted in spiked sample chromatogram; however, they did not interfere with vitamins quantitation.

Linearity was tested by running six standard mixtures of water-soluble vitamins at final, on-column concentrations of $0.5,1,2,5,10,15$, and $20 \mathrm{ng} \mu \mathrm{L}^{-1}$. The method was linear across the whole range of concentrations (Table 4).

For all peaks, there was a very tight relationship between the amount of vitamins and the detectors response as indicated by $R^{2}$ values that exceeded $0.996( \pm 0.002)$.

Linearity of the method was also investigated in spiked plasma samples (data not shown). No statistically significant difference was observed between slopes of regression lines generated by aqueous- and plasma-based standards (Student's $t$-test not significant, $P>0.05)$. So for quantitation purposes, aqueous-based standards were used to calibrate the instrument response when analysing trial samples. Calibration curves were constructed using six standard concentrations of eight water-soluble vitamins prepared in double distilled water, and they were run in triplicate. For each curve, peak-areas of vitamins were plotted against 
TABLE 4: Regression parameters of analysed vitamins. Regression parameters (regression equation $[ \pm \mathrm{SD}$ of slope and intercept] and regression coefficient) and detection limits (signal-to-noise ratio $=5$ and injection volume $=3 \mu \mathrm{L}$ ).

\begin{tabular}{lccc}
\hline Vitamin & $\begin{array}{c}\text { Limit of detection }\left[\mathrm{ng} \mu \mathrm{L}^{-1}\right] \text { at given } \mathrm{UV} \\
(\lambda,[\mathrm{nm}])\end{array}$ & Regression line & $\begin{array}{l}\text { Regression } \\
\text { coefficient }\end{array}$ \\
\hline $\mathrm{C}$ & $0.5 \mathrm{ng} \mu \mathrm{L}^{-1}(230 \mathrm{~nm})$ & $y=0.657( \pm 0.003) x+127.1( \pm 0.002)$ & $R^{2}=0.994$ \\
$\mathrm{~B}_{1}$ & $1 \mathrm{ng} \mu \mathrm{L}^{-1}(270 \mathrm{~nm})$ & $y=8.789( \pm 0.002) x+16.31( \pm 0.004)$ & $R^{2}=0.996$ \\
$\mathrm{~B}_{2}$ & $0.5 \mathrm{ng} \mu \mathrm{L}^{-1}(265 \mathrm{~nm})$ & $y=301.7( \pm 0.005) x+467.3( \pm 0.002)$ & $R^{2}=0.996$ \\
$\mathrm{~B}_{5}$ & $1 \mathrm{ng} \mu \mathrm{L}^{-1}(266 \mathrm{~nm})$ & $y=1.052( \pm 0.008) x+66.43( \pm 0.003)$ & $R^{2}=0.979$ \\
$\mathrm{~B}_{6}(\mathrm{PLP})$ & $0.5 \mathrm{ng} \mu \mathrm{L}^{-1}(257 \mathrm{~nm})$ & $y=7.451( \pm 0.003) x+12.81( \pm 0.004)$ & $R^{2}=0.997$ \\
$\mathrm{~B}_{9}$ & $1 \mathrm{ng} \mu \mathrm{L}^{-1}(280 \mathrm{~nm})$ & $y=246.1( \pm 0.002) x+54.31( \pm 0.005)$ & $R^{2}=0.999$ \\
$\mathrm{~B}_{12}$ & $2 \mathrm{ng} \mu \mathrm{L}^{-1}(230 \mathrm{~nm})$ & $y=132.9( \pm 0.007) x+209.6( \pm 0.008)$ & $R^{2}=0.995$ \\
\hline
\end{tabular}

the nominal (theoretical) vitamins concentration. Calibration curves were generated by weighted $(1 / y)$ linear regression analysis.

Detection/quantitation limits were determined by analysis of six standard solutions and three spiked plasma samples with final concentrations ranging from $0.5 \mathrm{ng} \mu \mathrm{L}^{-1}$ to $30 \mathrm{ng} \mu \mathrm{L}^{-1}$ each vitamin.

Precision of the method was evaluated by estimating the repeatability and intermediate precision of the analytical method. The repeatability was studied by running 10 consecutive replications of the same sample and calculating the \%RSD for peaks area and elution times (sample injection volume $=3 \mu \mathrm{L}$ ). The intermediate precision was calculated as the \%RSD of peaks area and elution times across three consecutive analytical days.

Values of \%RSD for retention times and peak areas obtained in the analysis of reproducibility and intermediate precision are presented in Table 5.

All RSD values were similar to those reported in the literature for within- and between-days variation [7, 10]. Results indicate that repeatability and the intermediate precision of the method were acceptable.

4.2. Stability, Carryover, and Recovery. Stability of vitamins stock solutions was tested by analysing aliquots stored at different temperatures (room temperature $\left[20^{\circ} \mathrm{C}\right],+4^{\circ} \mathrm{C}$, $-20^{\circ} \mathrm{C}$, and $-80^{\circ} \mathrm{C}$ ) at different time intervals (same day of preparation, 7 days, 14 days and 30 days). Aliquots were stored either in clear autosampler vials or amber glass autosampler vials to investigate the effect of photodegradation on vitamins. Experiments were run in triplicate and average peak area $( \pm \mathrm{RSD})$ was considered in calculations.

Results indicate that there is no statistically significant difference between standard solutions stored at $-20^{\circ} \mathrm{C}$ and $-80^{\circ} \mathrm{C}$ at every time point (Student's $t$-test not significant, $P>0.05)$; there is no statistically significant difference between standards kept at room temperature and $+4^{\circ} \mathrm{C}$ on the same day of preparation up to 14 days $(P>0.05)$, whereas a statistical significant difference can be observed after 30 days $(P<0.05$; exact $P=0.029)$. There is a statistical significant difference between standards kept at $+4^{\circ} \mathrm{C}$ and $-20^{\circ} \mathrm{C}$ after 30 days $(P<0.05$; exact $P=0.031)$ but no difference was noted between standards analysed on the same day of preparation, and after 7 and 14 days $(P>0.05)$.
TABLE 5: Retention times and peak areas of analysed vitamins. Relative standard deviations (\%RSD) of retention times and peak areas for 7 water-soluble vitamins spiked at $20 \mathrm{ng} \mu \mathrm{L}^{-1}$ in artificial plasma obtained in the analysis for repeatability and reproducibility.

\begin{tabular}{|c|c|c|c|c|}
\hline \multirow{2}{*}{ Vitamin } & \multicolumn{2}{|c|}{ Repeatability ${ }^{\mathrm{a}}$} & \multicolumn{2}{|c|}{ Reproducibility ${ }^{\mathrm{b}}$} \\
\hline & $\begin{array}{l}\text { Retention } \\
\text { time } \% \text { RSD }\end{array}$ & Area \%RSD & $\begin{array}{l}\text { Retention } \\
\text { time } \% \text { RSD }\end{array}$ & Area \%RSD \\
\hline $\mathrm{C}$ & $0.56 \%$ & $2.23 \%$ & $1.97 \%$ & $4.56 \%$ \\
\hline $\mathrm{B}_{1}$ & $0.99 \%$ & $3.65 \%$ & $2.76 \%$ & $6.89 \%$ \\
\hline $\mathrm{B}_{2}$ & $0.13 \%$ & $1.87 \%$ & $0.89 \%$ & $3.3 \%$ \\
\hline $\mathrm{B}_{5}$ & $0.90 \%$ & $2.25 \%$ & $2.75 \%$ & $4.1 \%$ \\
\hline PLP & $0.46 \%$ & $2.22 \%$ & $1.93 \%$ & $3.77 \%$ \\
\hline $\mathrm{B}_{9}$ & $0.18 \%$ & $2.69 \%$ & $1.2 \%$ & $2.98 \%$ \\
\hline$B_{12}$ & $0.67 \%$ & $2.98 \%$ & $2.37 \%$ & $6.07 \%$ \\
\hline
\end{tabular}

Photodegradation has a significant impact upon vitamins break down: in fact, a statistically significant difference was noted between standards prepared in clear and amber glass autosampler vials soon after 7 days when kept at room temperature $(P<0.05$; exact $P=0.017)$ and at $+4^{\circ} \mathrm{C}$ $(P<0.05$; exact $P=0.020)$; this difference increases over time, up to 30 days when the difference becomes statistically significant beyond $1 \%(P<0.01$; exact $P=0.0006)$. Ascorbic acid (vitamin $C$ ) and cyanocobalamin $\left(B_{12}\right)$ are the most sensitive to photodegradation.

Additionally, concentrations of vitamins were stable in processed (deproteinised) plasma samples and water-based controls for 24 hours when stored at $+4^{\circ} \mathrm{C}$ prior to analysis [difference between peak area of vitamins in standard samples and peak area of vitamins in processed samples did not reach statistical significance when stored at $+4^{\circ} \mathrm{C}$ for 24 hours, Student's $t$-test not significant, $P>0.05$ ].

Three freeze-thaw cycles had an effect on the stability of vitamins (Student's $t$-test significant beyond 5\%, exact $P=$ 0.041). There is no statistically significant difference between freshly prepared, water-based standard solutions, and an aliquot of the same stored at $-20^{\circ} \mathrm{C}$ after one cycle of freezethaw $(P>0.05)$, but the difference in peak area reaches statistical significance after two freeze-thaw cycles $(P<0.05$; exact $P=0.042$ ). In conclusion, standard solutions and trial samples can be stored at $-20^{\circ} \mathrm{C}$ until the day of analysis for 30 days but they cannot be frozen again. 
TABLE 6: Mean concentration of individual water-soluble vitamins ( \pm SEM) in plasma samples obtained from 24 study participants. Elevate variability in individuals' vitamin levels may explain high S.E.M.s in the case of $B_{1}, B_{5}$ and $B_{6}$.

\begin{tabular}{lccccccc}
\hline & $\mathrm{C}(\mu \mathrm{mol} \mathrm{L}$ \\
& 44.7 & $\mathrm{~B}_{1}\left(\mathrm{nmol} \mathrm{L}^{-1}\right)$ & $\mathrm{B}_{2}\left(\mathrm{nmol} \mathrm{L}^{-1}\right)$ & $\mathrm{B}_{5}\left(\mathrm{nmol} \mathrm{L}^{-1}\right)$ & $\mathrm{B}_{6}\left(\mathrm{nmol} \mathrm{L}^{-1}\right)$ & $\mathrm{B}_{9}\left(\mathrm{nmol} \mathrm{L}^{-1}\right)$ & $\mathrm{B}_{12}\left(\mathrm{nmol} \mathrm{L}^{-1}\right)$ \\
\hline Mean $(n=24)$ & 51.3 & 15.6 & 32.4 & 73.3 & 8.5 & 5.7 \\
S.E.M & 16.3 & 27.6 & 5.5 & 32.7 & 37.9 & 4.3 & 1.7 \\
Ref. value [1,2] & $24-84$ & $9-44$ & $6.2-39$ & N/A & $7-52$ & $3.1-18$ & $1.9-3.5$ \\
\hline
\end{tabular}

Ref. values: reference intervals obtained from Malmauret et al. 2002 [1] and from Talwar et al. [2].

TABLE 7: Average concentration of individual water-soluble vitamins $( \pm$ SEM $)$ in urine samples obtained from study participants.

\begin{tabular}{|c|c|c|c|c|c|c|c|}
\hline & $\mathrm{C}$ & $\mathrm{B}_{1}$ & $\mathrm{~B}_{2}$ & $\mathrm{~B}_{5}$ & $\mathrm{~B}_{6}$ & $\mathrm{~B}_{9}$ & $\mathrm{~B}_{12}$ \\
\hline $\begin{array}{l}\text { Average } \\
\text { concentration } \\
(n=24), \mathrm{mg} \mathrm{dL}^{-1}\end{array}$ & 0.04 & 0.15 & 0.01 & 0.14 & 0.23 & 0.02 & 0.02 \\
\hline S.E.M. $\left(\mathrm{mg} \mathrm{dL}^{-1}\right)$ & 0.02 & 0.03 & 0.00 & 0.01 & 0.09 & 0.01 & 0.01 \\
\hline Av. Creat. $\left(\mathrm{mg} \mathrm{dL}^{-1}\right)$ & 96.86 & 96.86 & 96.86 & 96.86 & 96.86 & 96.86 & 96.86 \\
\hline $\begin{array}{l}\text { Vitamin/creatinine } \\
\text { ratio }\end{array}$ & 0.00038 & 0.00153 & 0.00012 & 0.00143 & 0.00237 & 0.00020 & 0.00025 \\
\hline
\end{tabular}

There was no clear evidence of carryover in any blank reagent samples.

Recovery tests were performed in triplicate by spiking blank plasma sample before deproteinisation (with $200 \mu \mathrm{L}$ pure acetonitrile) and solid-phase extraction with $20 \mathrm{ng} / \mu \mathrm{L}$ of each vitamin. This concentration was selected as a compromise between the most possible plasma vitamins concentration to be found in real samples. Results were not significantly dissimilar to $100 \%$ [Student's $t$-test not significant, $P>0.05$ ]. Recovery experiments were repeated at $75 \%, 50 \%, 25 \%$, and $10 \%$ of the above vitamins concentrations. Recovery percentages ranged from $93 \%$ to $100 \%$ at all concentrations.

\section{Application}

Work with the participation of human subjects was conducted in accordance with the Declaration of Helsinki (1964). Twenty-four (24) abstinent alcohol-dependent males (average age: $51 \pm 6$ years old) undergoing alcohol rehabilitation agreed to have one blood and one urine sample taken to investigate their levels of water-soluble vitamins. All subjects who provided samples read, understood and signed a Participant Information Document. Ethical approval was obtained from both the University of Kent Ethics Committee (where the biochemical analyses were conducted) and from The Salvation Army Ethics Board (participants were residents in one Salvation Army Hostel near Swindon, UK).

Plasma samples were processed following the third methodology reported in Section 2 of this paper. Briefly, blood samples were withdrawn from participant using arm venipuncture, and plasma and serum fractions were immediately separated by centrifugation. Plasma fraction was used for the analysis of water-soluble vitamins. Plasma samples were treated with methanol: ethanol, $95: 5, \mathrm{v} / \mathrm{v}$ and then processed through solid-phase extraction.
Results from plasma and urine analyses are reported in Tables 6 and 7, respectively. Unfortunately, it was not possible to separate and quantify vitamin $\mathrm{B}_{3}$ in plasma and urine samples.

\section{Discussion}

This paper reported the development and validation of a novel analytical method for the simultaneous detection and quantification of seven water-soluble vitamins in biological fluids (plasma and urine). The method has been shown to be robust and time-effective in the clinical routine practice. The application of this method to the analysis of water-soluble vitamins in plasma and urine samples of 24 abstinent alcohol-dependent males proved that the method is sensitive enough to detect low levels of analytes in complex matrices. This study provides an innovative approach to the simultaneous detection of seven water-soluble vitamins that has a wide range of application in clinical routine investigations.

\section{Conclusions}

The novel analytical method detailed in this paper has proved to be specific, robust, and time-efficient for the simultaneous detection and quantitation of water-soluble vitamins in complex biological matrices such as plasma and urine. This method can be used in routine clinical investigations where multivitamin analysis is required and low concentrations of vitamins are expected.

\section{References}

[1] L. Malmauret, J. C. Leblanc, I. Cuvelier, and P. Verger, "Dietary intakes and vitamin status of a sample of homeless people in Paris," European Journal of Clinical Nutrition, vol. 56, no. 4, pp. 313-320, 2002. 
[2] D. K. Talwar, M. K. Azharuddin, C. Williamson, Y. P. Teoh, D. C. McMillan, and D. S. J. O'Reilly, "Biological variation of vitamins in blood of healthy individuals," Clinical Chemistry, vol. 51, no. 11, pp. 2145-2150, 2005.

[3] A. D. Thomson, C. C. H. Cook, R. Touquet, and J. A. Henry, "The Royal College of physicians report on alcohol: guidelines for managing Wernicke's encephalopathy in the accident and emergency department," Alcohol and Alcoholism, vol. 37, no. 6, pp. 513-521, 2002.

[4] J. T. Tanner and S. A. Barnett, "Methods of analysis for infant formula. Food and Drug Administration and Infant Formula Council Collaborative Study, Phase III," Journal of Association of Official Analytical Chemists, vol. 69, no. 5, pp. 777-785, 1986.

[5] M. Shabangi and J. A. Sutton, "Separation of thiamin and its phosphate esters by capillary zone electrophoresis and its application to the analysis of water-soluble vitamins," Journal of Pharmaceutical and Biomedical Analysis, vol. 38, no. 1, pp. 66-71, 2005.

[6] C. Yin, Y. Cao, S. Ding, and Y. Wang, "Rapid determination of water- and fat-soluble vitamins with microemulsion electrokinetic chromatography," Journal of Chromatography A, vol. 1193, no. 1-2, pp. 172-177, 2008.

[7] A. R. Ghorbani, F. Momenbeik, J. H. Khorasani, and M. K. Amini, "Simultaneous micellar liquid chromatographic analysis of seven water-soluble vitamins: optimization using supermodified simplex," Analytical and Bioanalytical Chemistry, vol. 379, no. 3, pp. 439-444, 2004.

[8] P. F. Chatzimichalakis, V. F. Samanidou, R. Verpoorte, and I. N. Papadoyannis, "Development of a validated HPLC method for the determination of B-complex vitamins in pharmaceuticals and biological fluids after solid phase extraction," Journal of Separation Science, vol. 27, no. 14, pp. 1181-1188, 2004.

[9] A. Gentili, F. Caretti, G. D'Ascenzo et al., "Simultaneous determination of water-soluble vitamins in selected food matrices by liquid chromatography/electrospray ionization tandem mass spectrometry," Rapid Communications in Mass Spectrometry, vol. 22, no. 13, pp. 2029-2043, 2008.

[10] B. Klejdus, J. Petrlová, D. Potěšil et al., "Simultaneous determination of water- and fat-soluble vitamins in pharmaceutical preparations by high-performance liquid chromatography coupled with diode array detection," Analytica Chimica Acta, vol. 520, no. 1-2, pp. 57-67, 2004.

[11] O. Heudi, T. Kilinç, and P. Fontannaz, "Separation of watersoluble vitamins by reversed-phase high performance liquid chromatography with ultra-violet detection: application to polyvitaminated premixes," Journal of Chromatography A, vol. 1070, no. 1-2, pp. 49-56, 2005.

[12] A. Oyane, H. M. Kim, T. Furuya, T. Kokubo, T. Miyazaki, and T. Nakamura, "Preparation and assessment of revised simulated body fluids," Journal of Biomedical Materials Research A, vol. 65, no. 2, pp. 188-195, 2003. 


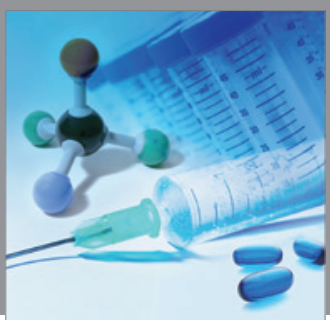

International Journal of

Medicinal Chemistry

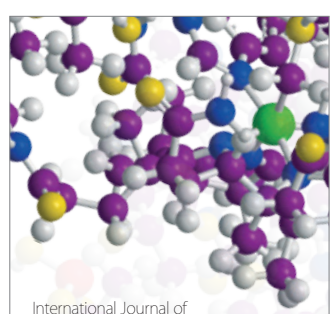

Carbohydrate Chemistry

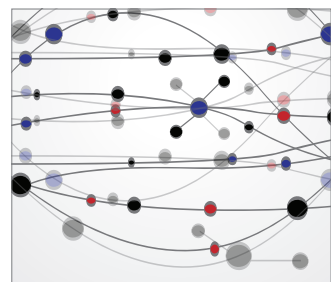

The Scientific World Journal
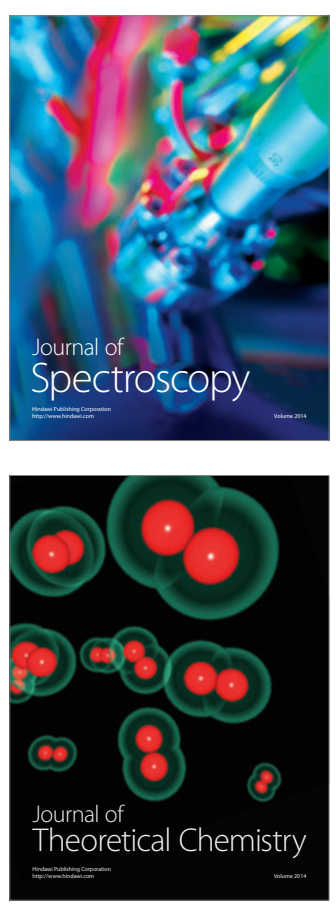
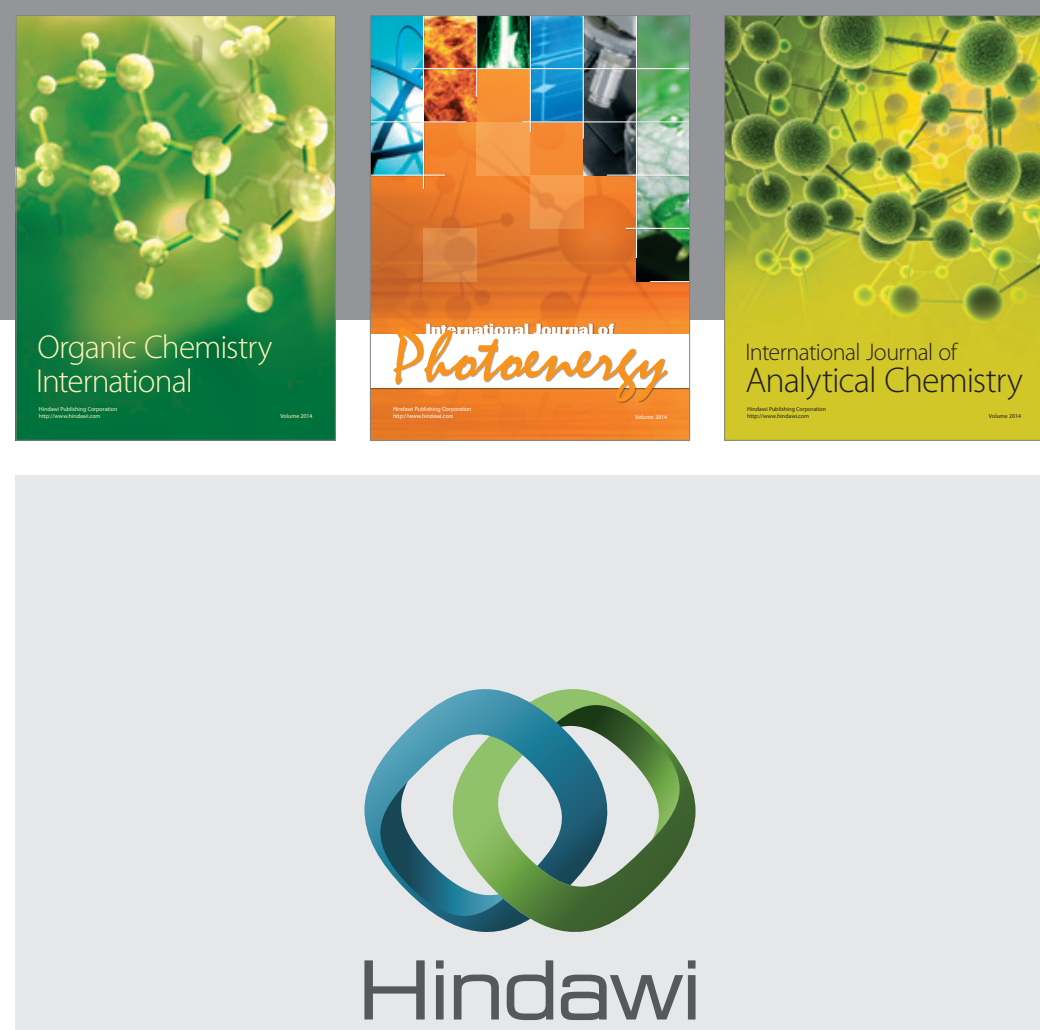

Submit your manuscripts at

http://www.hindawi.com
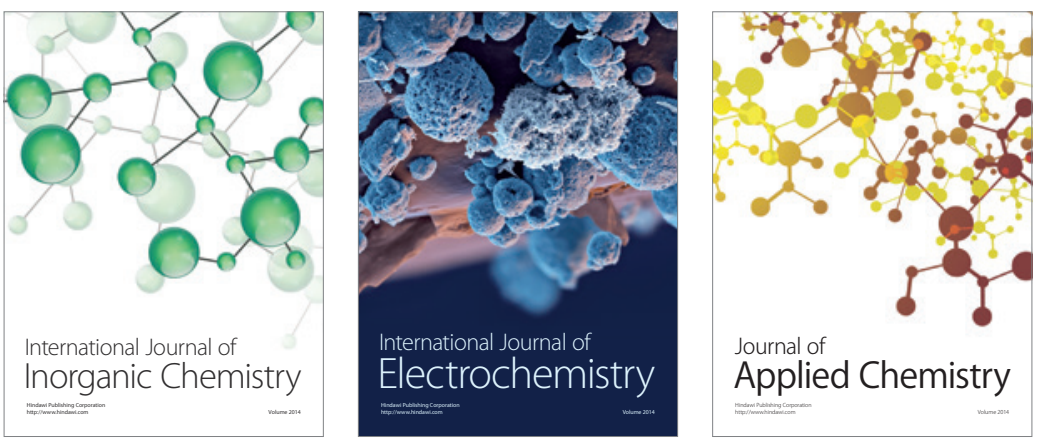

Journal of

Applied Chemistry
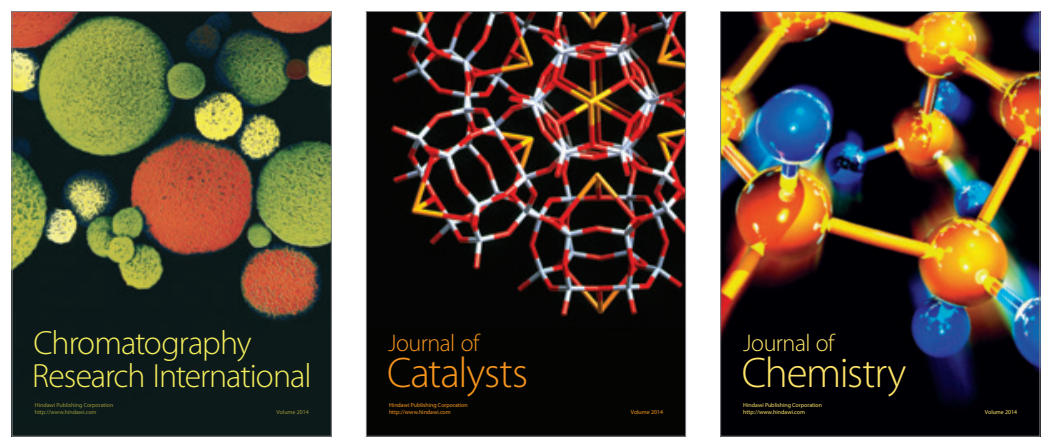
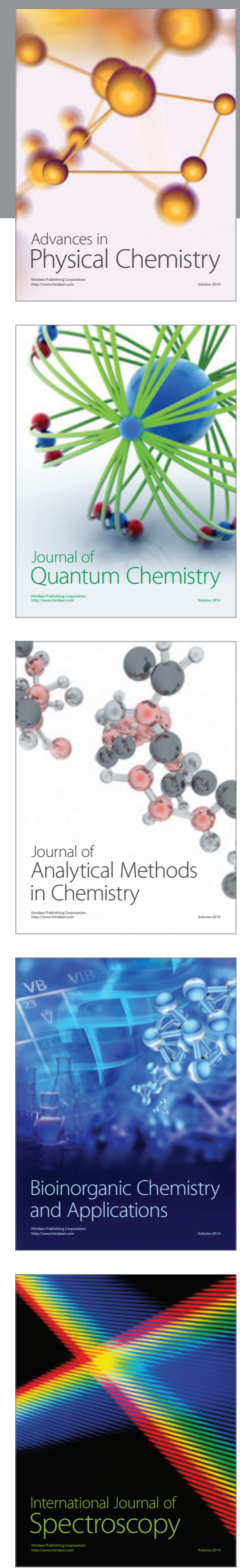